Article

\title{
Cellulase-Assisted Extraction of Polysaccharides from White Hyacinth Bean: Characterization of Antioxidant Activity and Promotion for Probiotics Proliferation
}

\author{
Guo-Wei Shu ${ }^{1}$ (D), Yun-Xia He ${ }^{1, *}$, Ni Lei ${ }^{1}$, Ji-Li Cao ${ }^{2}$, He Chen ${ }^{1}$ and Li Chen ${ }^{3, *}$ \\ 1 School of Food and Biological Engineering, Shaanxi University of Science and Technology, Xi'an 710021, \\ China; shuguowei@gmail.com (G.-W.S.); lily46569@163.com(N.L.); chenhe419@gmail.com (H.C.) \\ 2 Department of Research and Development, Xi'an Oriental Dairy Co., Ltd., Xi'an 710027, China; \\ xiandfcjl@gmail.com \\ 3 College of Food Engineering and Nutritional Science, Shaanxi Normal University, Xi'an 710119, China \\ * Correspondence: heyunxia63682@163.com (Y.-X.H.); chenlisp@snnu.edu.cn (L.C.); \\ Tel.: +86-159-9177-8350 (Y.-X.H.); Tel./Fax: +86-029-8531-0517 (L.C.)
}

Received: 13 September 2017; Accepted: 17 October 2017; Published: 20 October 2017

\begin{abstract}
Food-derived polysaccharides have advantages over synthetical compounds and have attracted interest globally for decades. In this study, we optimized the cellulase-assisted extraction of polysaccharides from white hyacinth bean (PWBs) with the aid of response surface methodology (RSM). The optimum extraction parameters were a $\mathrm{pH}$ of 7.79 , a cellulase of $2.73 \%$, and a ratio of water to material of 61.39 , producing a high polysaccharide yield $(3.32 \pm 0.03) \%$. The scavenging ability of PWBs varied on three radicals (hydroxyl > 2,2-diphenyl-1-picrylhydrazyl $(\mathrm{DPPH})>$ superoxide). Furthermore, PWBs contributed to the proliferation of three probiotic bacteria (Lactobacillus acidophilus LA5, Bifidobacterium bifidum BB01, and Lactobacillus bulgaricus LB6). These investigations of PWBs provide a novel bioresource for the exploitation of antioxidant and probiotic bacterial proliferation.
\end{abstract}

Keywords: white hyacinth bean polysaccharides; cellulase-assisted extraction; probiotics proliferation; antioxidant activities; response surface methodology

\section{Introduction}

Reactive oxygen species (ROS) is the chemical active products produced by the partial reduction of oxygen [1], which contributes to various pathological processes such as aging, inflammation, cancer, and atherosclerosis [2,3]. Free radicals can severely impact the quality and safety of food products due to lipid peroxidation [4]. Scavenging free radicals could weaken oxidative activity, which brings on a higher nutritional quality and a longer shelf-life of product. Therefore, the application of synthetic antioxidants in food and cosmetics has been well developed [5]. However, it has been reported that synthetic antioxidant might be related to neoplasia and liver damage [6]. Natural antioxidants such as polysaccharides from plants are characterized by excellent antioxidant activity and nontoxicity. Petera et al. [7] reported that polysaccharides extracted from Cereus triangularis cladodes showed lower antioxidants activities than mucilage extracted from peeled Opuntia ficus-indica fruits. Polysaccharide from Phellinus nigricans mycelia exhibited positive radical-scavenging activities against superoxide anion, hydroxyl, and 2,2-diphenyl-1-picrylhydrazyl (DPPH) radicals [8]. Delattre et al. [9] found that the modification of polysaccharides via regioselective oxidation had a positive effect on scavenging DPPH radical ability. Replacing synthetic antioxidants with natural substances has been a focus of pharmacologists and biologists for decades [10-13]. 
White hyacinth bean, the mature seed of Dolichos lablab L., has the concomitant function of both medicine and foodstuff. It has been widely planted in tropic and subtropic areas [14]. Polysaccharides are vital components of white hyacinth bean and are highly correlated with antioxidant activity. Common methods of extracting natural polysaccharides include ultrasound-assisted extraction, microwave-assisted extraction, acidic hydrolysis, and enzyme-assisted extraction. Enzyme-assisted extraction possesses several advantages, such as high efficient and extraction yield, low energy consumption, high efficiency, and easy operation [15]. However, the enzyme-assisted extraction of polysaccharides from white hyacinth bean (PWBs) and the application of these polysaccharides as antioxidants are not common due to a scarcity of the requisite materials.

Probiotic bacteria are living microorganisms that, when administered in adequate amounts, confer a health benefit on the host, and they are essential to the homeostasis and health of the gastrointestinal tract for human beings. Prebiotics are the non-digestible food ingredients that are actually used to stimulate the growth of probiotics. The combination of probiotics and prebiotics has a synergic effect on host health. The extraction of polysaccharides from natural sources is currently gaining attention for their potential prebiotic properties. Polysaccharides served as prebiotics could advance the growth of beneficial lactic acid bacteria in the colon [16].

We have carried out single-factor tests to study the effects of cellulase, pectinase, and xylanase on the extraction of PWBs. The Plackett-Burman and steepest ascent experiment showed that $\mathrm{pH}$, the addition amount of cellulase and the ratio of water to material were main factors for polysaccharide yield [17]. In the present study, the extraction conditions of PWBs were optimized by a central composite design (CCD). The scavenging activity of PWBs with respect to DPPH radicals, hydroxyl radicals, and superoxide radicals was determined. To our knowledge, studies concerning the prebiotic activity of PWBs are rare. Thus, the effect of PWBs on the growth of three selected probiotics-Lactobacillus bulgaricus (LB6), Lactobacillus acidophilus (LA5), and Bifidobacterium bifidum (BB01)—was also studied.

\section{Results and Discussion}

\subsection{Optimization of Cellulase-Assisted Extraction of PWBs by Response Surface Methodology}

The optimal combination of three independent variables, $\mathrm{pH}$ value (A), cellulase (B), and the ratio of water to material $(\mathrm{C})$, was studied using a CCD. The experimental design and the result of response value $\mathrm{Y}$ (polysaccharide yield) according to RSM are given in Table 1.

Design-Expert software was used to build the response surface model and analyze the data given in Table 2. The regression equation of this experiment is

$$
\mathrm{R} 1=3.31+0.10 \mathrm{~A}+0.10 \mathrm{~B}-0.16 \mathrm{C}-0.07 \mathrm{AB}+0.14 \mathrm{AC}-0.21 \mathrm{BC}-0.17 \mathrm{~A}^{2}-0.35 \mathrm{~B}^{2}-0.16 \mathrm{C}^{2}
$$

In this equation, $\mathrm{R} 1$ means the polysaccharide yield. $\mathrm{A}, \mathrm{B}$, and $\mathrm{C}$ represent the coded values of $\mathrm{pH}$ value, cellulase (\%), and the ratio of water to material, respectively.

The regression equation obtained was evaluated by analysis of variance (ANOVA) and tested the level of significance. The results are shown in Table 2. The $p$-value of the model obtained was smaller than 0.001 , showing the high significance of the regression model. In addition, all of the one-degree term and squares of this regression equation are significant, which suggests the relation between the response value and the factors are not a simple linear relation. The $p$-value of AC was lower than 0.01 , which represents a significant interaction between $\mathrm{pH}$ and the ratio of water to material. A similar interaction was observed between this ratio and cellulase. However, the interaction between $\mathrm{pH}$ and cellulase was non-significant. The coefficient of the $\mathrm{R}^{2}$ value of 0.9620 illustrated that $96.20 \%$ of the total variation in the response was explained by the model. The Adj $R^{2}$ value of 0.9278 close to the $R^{2}$ value showed the significance of the model, which indicated a good relationship between the predictive and the measured value of PWB yield. The value of PRESS (predicted residual sum of square) was 0.996, which indicates that the degree of fitting is workable. The SNR (signal-to-noise ratio) of 4.081 $(>4)$ implied that the model is satisfactory. Adequate precision is a measure of the range in predicted 
response relative to its associated error. The adequate precision value was 14.2808 greater than 4 , indicating that the models of response surface can be used to navigate the design space. Thus, it can be concluded that the model is adequate to describe the PWB extraction yield via RSM.

Table 1. The experimental design and results of the central composite design (CCD).

\begin{tabular}{ccccccc}
\hline \multirow{2}{*}{ Run } & \multicolumn{2}{c}{ Coded Variable Levels } & \multicolumn{3}{c}{ Polysaccharide Yield Y (\%) } \\
\cline { 2 - 6 } & $\mathbf{A}$ & $\mathbf{B}$ & $\mathbf{C}$ & Actual Value $\mathbf{Y}$ & Predicted Value $\mathbf{Y}^{\prime}$ & Residual $\mathbf{Y}-\mathbf{Y}^{\prime}$ \\
\hline 1 & 1.682 & 0 & 0 & 3.07 & 2.99 & 0.076 \\
2 & -1 & 1 & -1 & 3.18 & 3.20 & -0.022 \\
3 & 0 & 0 & 0 & 3.23 & 3.31 & -0.082 \\
4 & -1.682 & 0 & 0 & 2.60 & 2.66 & -0.062 \\
5 & -1 & -1 & 1 & 2.15 & 2.27 & -0.12 \\
6 & 1 & -1 & -1 & 2.38 & 2.50 & -0.12 \\
7 & 0 & 0 & 0 & 3.41 & 3.31 & 0.098 \\
8 & 0 & 0 & -1.682 & 3.07 & 3.13 & -0.056 \\
9 & -1 & -1 & -1 & 2.57 & 2.45 & 0.12 \\
10 & 0 & 0 & 0 & 3.26 & 3.31 & -0.052 \\
11 & 1 & 1 & -1 & 3.09 & 2.98 & 0.11 \\
12 & 1 & 1 & 1 & 2.40 & 2.53 & -0.13 \\
13 & 0 & 0 & 0 & 3.37 & 3.31 & 0.058 \\
14 & 0 & 0 & 0 & 3.31 & 3.21 & -0.0021 \\
15 & 0 & 1.682 & 0 & 2.43 & 2.48 & -0.046 \\
16 & 0 & -1.682 & 0 & 2.20 & 2.14 & 0.060 \\
17 & 0 & 0 & 1.682 & 2.67 & 2.60 & 0.069 \\
18 & 0 & 0 & 0 & 3.29 & 3.31 & -0.022 \\
19 & 1 & -1 & 1 & 2.90 & 2.89 & 0.013 \\
20 & -1 & 1 & 1 & 2.31 & 2.19 & 0.12 \\
\hline
\end{tabular}

Table 2. The ANOVA of the CCD.

\begin{tabular}{ccccccc}
\hline Source & SS & DF & MS & F & Pr $>$ F & Sig \\
\hline Model & 3.409 & 9 & 0.379 & 28.109 & $<0.0001$ & $* * *$ \\
A & 0.134 & 1 & 0.134 & 9.909 & 0.0104 & $*$ \\
B & 0.137 & 1 & 0.137 & 10.150 & 0.0097 & $* *$ \\
C & 0.333 & 1 & 0.333 & 24.714 & 0.0006 & $* * *$ \\
AB & 0.039 & 1 & 0.039 & 2.909 & 0.1189 & \\
AC & 0.157 & 1 & 0.157 & 11.635 & 0.0066 & $* *$ \\
BC & 0.344 & 1 & 0.344 & 25.559 & 0.0005 & $* * *$ \\
A $^{2}$ & 0.422 & 1 & 0.422 & 31.299 & 0.0002 & $* * *$ \\
B $^{2}$ & 1.815 & 1 & 1.815 & 134.713 & $<0.0001$ & $* * *$ \\
C $^{2}$ & 0.363 & 1 & 0.363 & 26.935 & 0.0004 & $* * *$ \\
Residual error & 0.135 & 10 & 0.013 & & & \\
Lack of fit & 0.112 & 5 & 0.022 & 4.889 & 0.0532 & \\
Pure error & 0.023 & 5 & 0.005 & & & \\
Total & 3.544 & 19 & & & & \\
\hline
\end{tabular}

DF: Degree of freedom; Pr: Probability; SS: Sum of squares; MS: Mean square; ${ }^{*} p<0.05,{ }^{* *} p<0.01,{ }^{* * *} p<0.001$, $R^{2}=96.20 \%$, Radj $^{2}=92.78$.

Using software (Design-Expert 8.0.6) to analyze the regression equation, the response surface plot and contour plot obtained with Equation (1) were produced and are shown in Figure 1. 


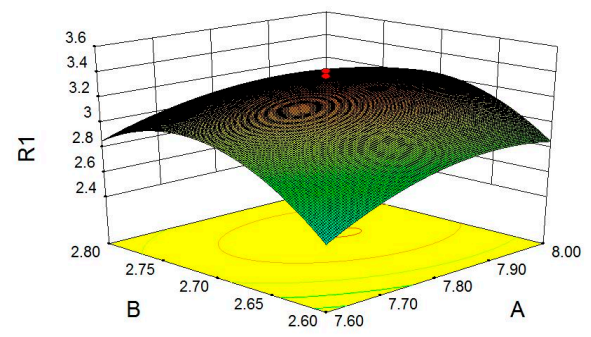

(a)

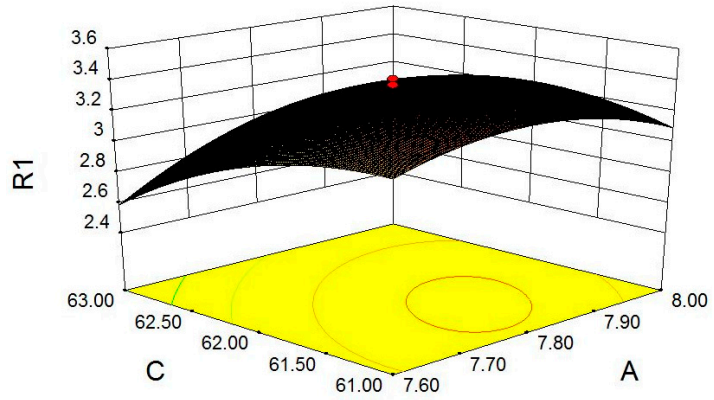

(c)

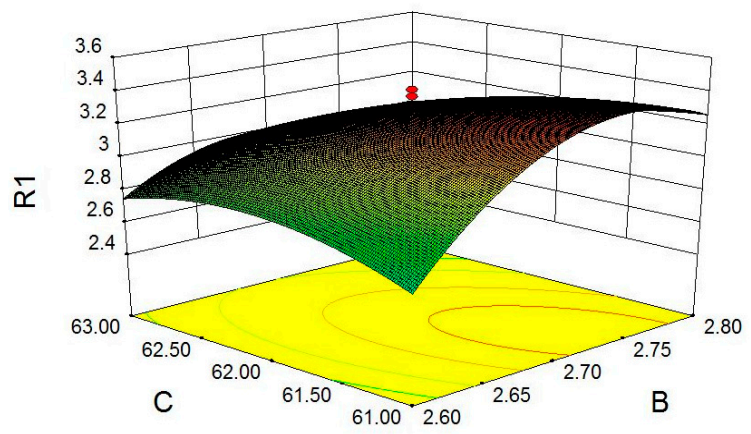

(e)

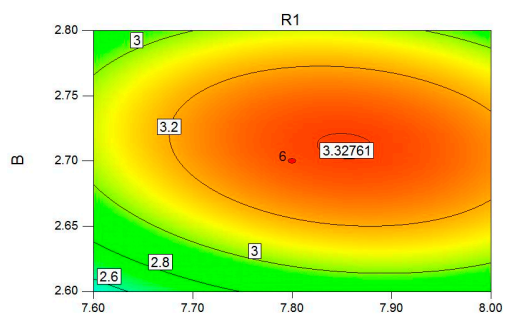

(b)

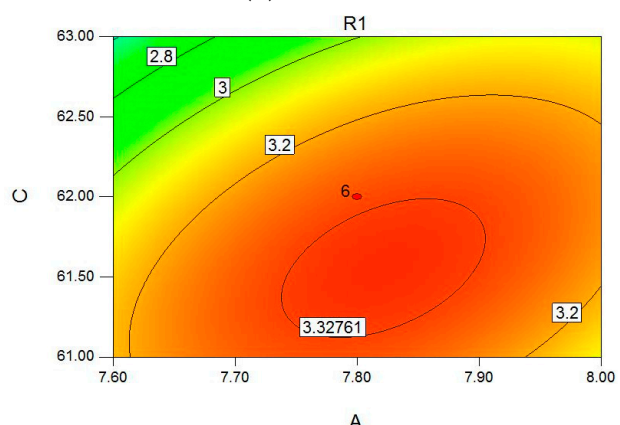

(d)

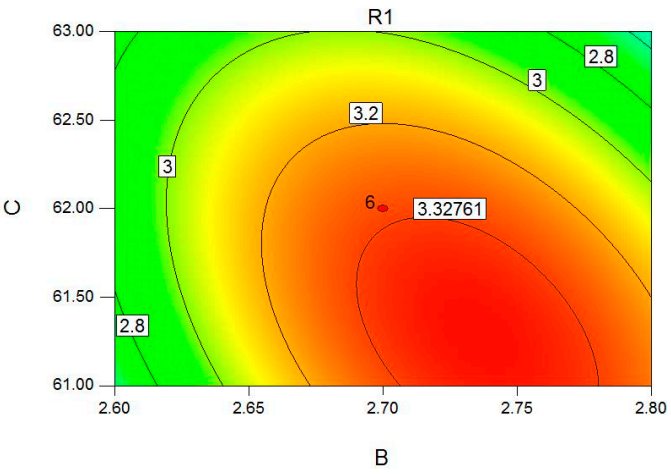

(f)

Figure 1. Response surface plot and contour plot showing interaction effects of A (pH value) and B (cellulase) (a,b), A ( $\mathrm{pH}$ value) and C (ratio of water to material) (c,d), B (cellulase) and C (ratio of water to material) $(\mathbf{e}, \mathbf{f})$ on the polysaccharide yield.

It is necessary to check the fitted model to ensure that it provides an adequate approximation to the real system. The investigation and optimization of the fitted response surface likely give misleading results if the model is not very adequate. The residuals in the least squares fit are very vital in checking the adequacy of model. By constructing a normal probability plot of the residuals, a check was made for the normality assumption, as given in Figure 2. The normality assumption was satisfied as the residual plot approximated along a straight line. Figure 2 also presents a plot of residuals vs. the predicted response. The general impression is that the residuals scatter randomly on the display, suggesting that the variance of the original observation is constant for all values of $Y$. These two plots are satisfactory.

By solving the inverse matrix of the quadratic polynomial equation employing the software of Design-Expert 8.0.6, the optimum values of the tested independent variables were a $\mathrm{pH}$ of 7.79, a cellulase of $2.73 \%$, and a ratio of water to material of 61.39 . Under the optimum conditions, the predicted polysaccharide yield reached a maximum of $3.37 \%$. The confirmatory experiments were conducted under optimized conditions in order to test and verify the optimized result. Under the determined conditions, the mean value of polysaccharide yield was $(3.32 \pm 0.03) \%$, which is slightly lower than the predicted maximum value, indicating the model designed in this study is valid to optimize the extraction of polysaccharide. 


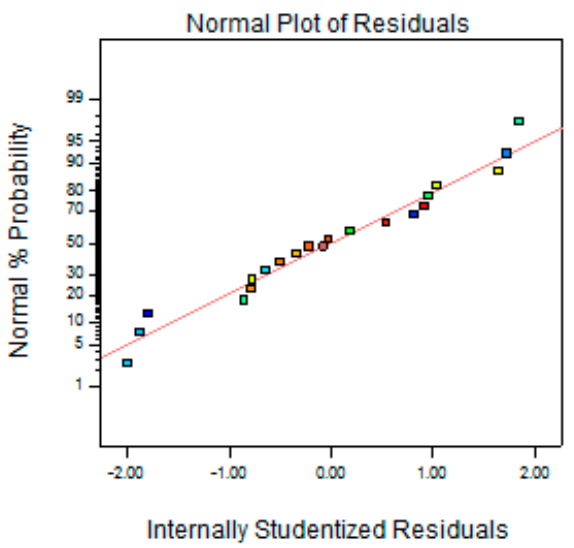

(a)

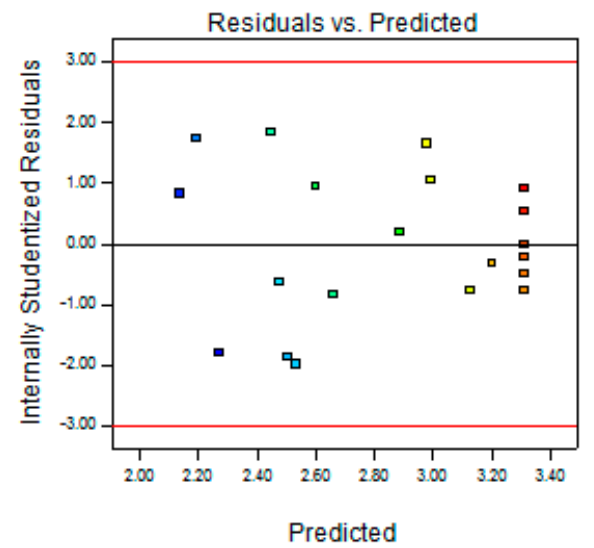

(b)

Figure 2. (a) Normal probability of internally studentized residuals; (b) Plot of internally studentized residuals vs. predicted response.

\subsection{Antioxidant Activities of PWBs}

\subsubsection{Hydroxyl Radical-Scavenging Activity}

Hydroxyl radicals have been identified as strong oxidants that can produce severe damage to the biomolecules [18], so it is necessary to scavenge or decrease the concentration of hydroxyl radicals. The scavenging hydroxyl radical activities of PWBs and ascorbic acid $\left(\mathrm{V}_{\mathrm{C}}\right)$ are shown in Figure $3 \mathrm{a}$. It is clear that the PWBs and $\mathrm{V}_{C}$ both had the ability to scavenge hydroxyl radicals. As shown in Figure $3 a$, the scavenging ability varied in a concentration-dependent manner, which grew with the increase in the concentration of PWBs and $\mathrm{V}_{C}$. The scavenging activity against hydroxyl radicals showed rapid growth at the low concentration of $2 \mathrm{mg} \cdot \mathrm{mL}^{-1}$, which was $35 \%$ and $62.05 \%$ for PWBs and ascorbic acid, respectively. The scavenging activity of PWBs was lower than that of Vc within the tested concentration range. When the PWB concentration increased to $10 \mathrm{mg} \cdot \mathrm{mL}^{-1}$, the scavenging activity reached $59 \%$, which was equal to the $79.12 \%$ of $\mathrm{V}_{C}$ (used as standard) scavenging activity at same concentration. These results suggested that PWBs had significant scavenging ability with respect to hydroxyl radicals. The mechanism of the hydroxyl radical-scavenging activity of PWBs might be that the existence of numerous hydrogen donors in the polyhydroxy structures of PWBs, which have a strong affinity for hydroxyl radicals, can quickly capture hydrogen atoms in $\mathrm{C}-\mathrm{H}$ chains and produce water. The carbon atom decomposes into harmless products after a range of reactions, resulting in the termination of free radical chain reactions [19].

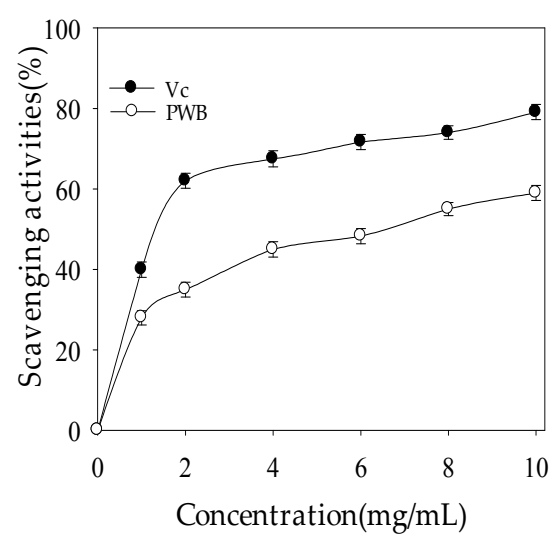

(a)

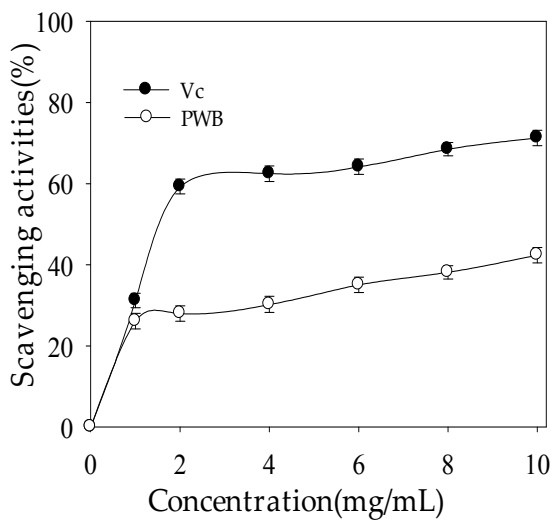

(b)

Figure 3. Cont. 


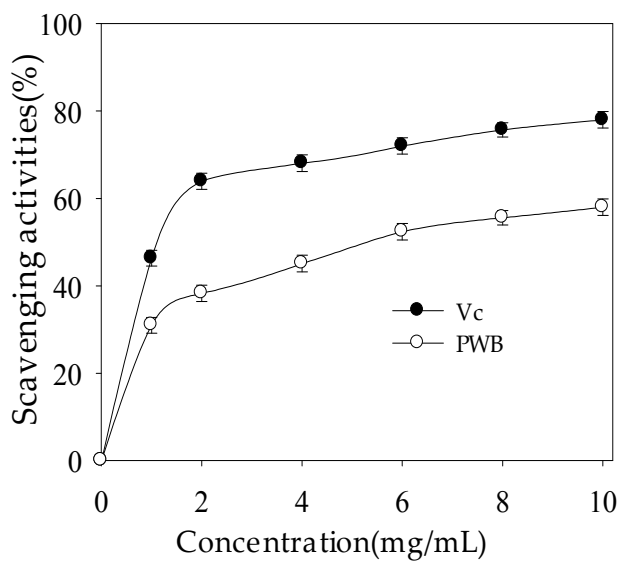

(c)

Figure 3. Scavenging activities of $\mathrm{PWBs}$ and ascorbic acid $\left(\mathrm{V}_{\mathrm{C}}\right)$ with respect to the hydroxyl radicals (a); superoxide radicals (b); and DPPH radicals (c). All values are represented as mean \pm standard deviation $(n=3)$.

\subsubsection{Superoxide Radical-Scavenging Activity}

Superoxide anion radicals, some of the strongest reactive oxygen species among the free radicals, can be converted to harmful ROS such as hydrogen peroxide, hydroxyl radicals, and damaging biomolecules that result in chronic diseases [20]. Superoxide anion radicals are generated by enzyme systems, such as peroxidase, NADPH oxidase, and xanthine oxidase. Antioxidants can delay the oxidation process by inhibiting the polymerization chain initiated by free radicals and other subsequent oxidizing reactions. When superoxide anion radicals were scavenged by antioxidants, the absorbance at $320 \mathrm{~nm}$ increased due to the color change from purple to yellow [21], which indicates the antioxidant ability of polysaccharides. The results of scavenging the superoxide radical activities of polysaccharides and ascorbic acid can be seen in Figure 3b. Similar to the scavenging hydroxyl radical activities, the scavenging activities of polysaccharides and ascorbic acid on superoxide radicals increased with the rise in concentration. At the high concentration of $10 \mathrm{mg} \cdot \mathrm{mL}^{-1}$, the levels of superoxide radical scavenging were $42.4 \%$ and $71.3 \%$ for PWBs and ascorbic acid, respectively. The mechanism of superoxide radical-scavenging activity might be that an oxidation reaction occurs between PWBs and superoxide anion radicals, contributing to the effect of scavenging superoxide radicals [19].

\subsubsection{DPPH Radical-Scavenging Activity}

DPPH radicals, important compounds that possess proton free radicals, decrease greatly when exposed to proton radical scavengers [22]. Figure $3 \mathrm{c}$ depicts the scavenging ability of polysaccharides and ascorbic acid with respect to DPPH radicals. The results suggest that polysaccharides and ascorbic acid can both scavenge DPPH radicals. There was a positive correlation between scavenging activity and polysaccharide concentration. However, it was noted that, for all concentrations ( 0 to $\left.10 \mathrm{mg} \cdot \mathrm{mL}^{-1}\right)$, the DPPH radical scavenging activities of polysaccharides were always lower than those of ascorbic acid. When polysaccharides amounted to $10 \mathrm{mg} \cdot \mathrm{mL}^{-1}$, the scavenging activity with respect to DPPH radicals reached $58 \%$, which was almost $78 \%$ of the scavenging activity of $V_{C}$ at the same concentration. The scavenging activity of PWBs in terms of DPPH may be due to the existence of the numerous hydroxyls in the polysaccharide molecule, which might serve as an electron donator and transfer electrons to DPPH free radicals [23]. Therefore, polysaccharides and ascorbic acid both showed scavenging activity on the hydroxyl radicals, superoxide radicals, and DPPH radicals. However, their scavenging abilities were different. These observations suggest that the scavenging activity of polysaccharides was lower compared to that of the $\mathrm{V}_{\mathrm{C}}$. It has been proven that polysaccharides obtained from plants have excellent antioxidant activity. Previous research has shown 
that polysaccharides contribute greatly to anti-tumor activity, lower blood pressure, and cholesterol [11]. The antioxidant activity of polysaccharides could be affected by many different factors, such as their chemical structure, molecular weight, degree of branching, and chemical composition [24,25]. PWBs are crude and water-soluble, so it is necessary and essential to complete further purification.

\subsection{Effect of Polysaccharide on the Growth of Three Selected Probiotics}

The effect of polysaccharides on the growth of L. acidophilus LA5 is shown in Figure 4a,b. It suggested that the promotion effect of polysaccharides on L. acidophilus LA5 was related to the addition of polysaccharide. Within $0.2 \%$, the promotion effect of polysaccharides on L. acidophilus LA5 increased as the addition of polysaccharide. When the polysaccharide addition was $0.20 \%$, the OD value and $\mathrm{pH}$ value tended to be stable. These could be explained by the change of osmotic pressure and $\mathrm{pH}$ value. Metabolites accumulated and finally resulted in limitation of L. acidophilus LA5 proliferation. The effect of polysaccharides on the growth of B. bifidum BB01 was shown in Figure 4c,d. Similar to the L. acidophilus LA5, a concentration-dependent manner was observed for the prebiotic effect of PWBs on the growth of B. bifidum BB01. When the addition was $0.20 \%$, the OD value and the $\mathrm{pH}$ value were tended to be stable. Figure $4 \mathrm{e}, \mathrm{f}$ showed the effect of polysaccharides on the growth of L. bulgaricus LB6. The results suggested that the promotion effect of polysaccharides on L. bulgaricus LB6 was related to the addition of polysaccharide. The promotion effect had an obvious enhancement with the increase of polysaccharide addition.

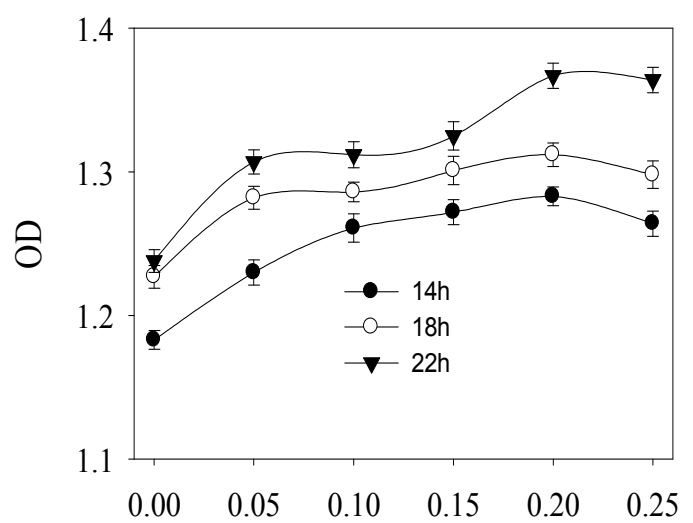

Concentration of $\mathrm{PWB}(\%)$

(a)

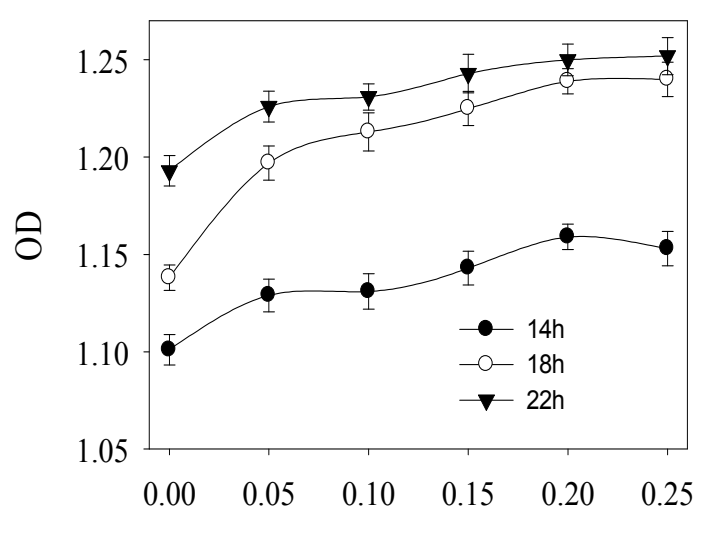

Concentration of $\mathrm{PWB}(\%)$

(c)

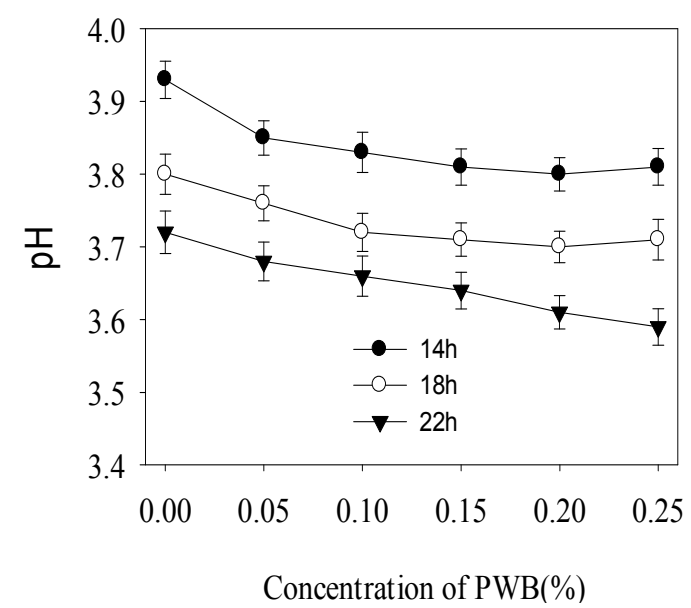

(b)

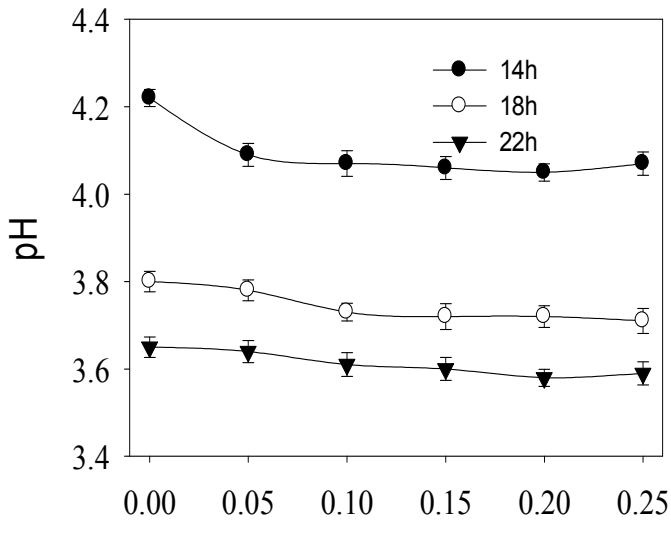

Concentration of $\mathrm{PWB}(\%)$

(d)

Figure 4. Cont. 


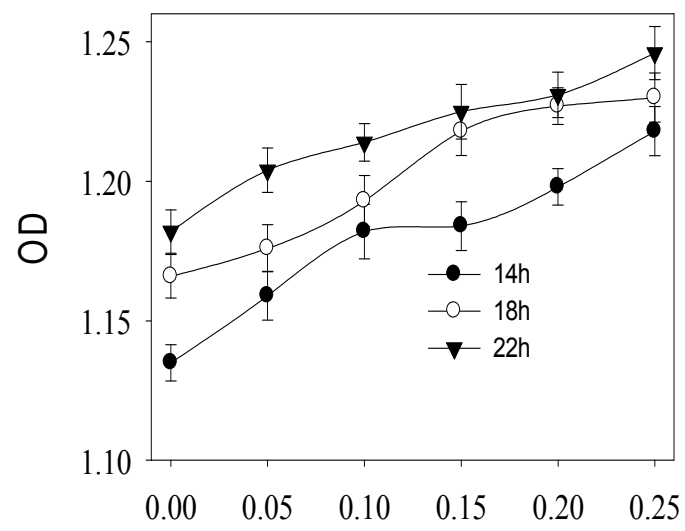

Concentration of $\mathrm{PWB}(\%)$

(e)

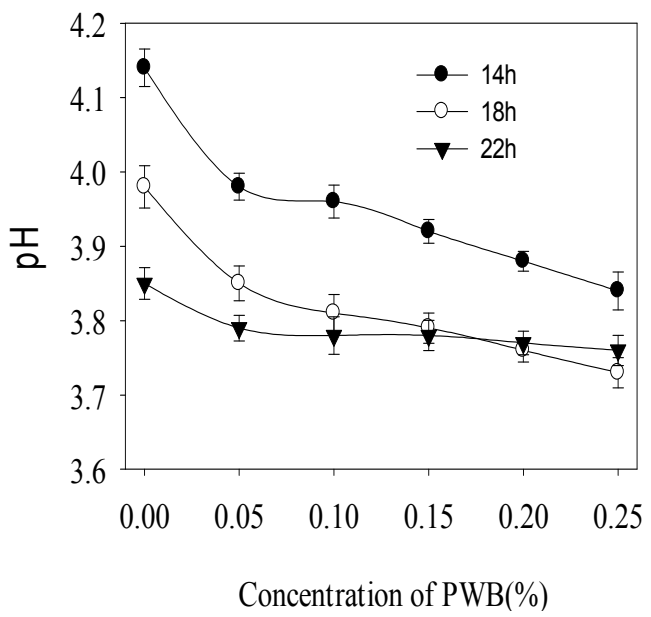

(f)

Figure 4. Effects of PWBs on the growth of Lactobacillus acidophilus LA5 (a,b), Bifidobacterium bifidum BB01 $(\mathbf{c}, \mathbf{d})$, and Lactobacillus bulgaricus LB6 $(\mathbf{e}, \mathbf{f})$. All values are represented as mean \pm standard deviation $(n=3)$.

Taken together, PWBs exhibited a different prebiotic effect on these three probiotics (L. acidophilus LA5, B. bifidum BB01, and L. bulgaricus LB6). The ability of probiotics to degrade and ferment polysaccharides varies greatly among different species of $L A B$ even among strains of the same species [26]. L. acidophilus LA5, B. bifidum BB01, and L. bulgaricus LB6 are three common probiotics, which have been used in many foods, especially yogurt. Similar results were found by Mueller [27], who found that the neutral polysaccharides from Hyptis suaveolens significantly induced the growth of L. acidophilus, L. paracasei DN114001, DSM20312, and CRL431, L. reuteri, L. rhamnosus GG, B. infantis, L. brevis, Lc. lactis, L. fermentum, and S. thermophilus. Madhukumar and Muralikrishna [28] reported that xylooligosaccharides extracted from bengal gram husk and wheat bran served as active prebiotic components. Numerous studies on the prebiotic potential of polysaccharides extracted from natural sources have been reported such as brown seaweed [29] and ginseng [30]. Polysaccharides served as a carbon resource in the metabolic process of probiotics can be disintegrated into monosaccharides, which can provide energy for probiotics. Meanwhile, probiotics can produce organic acid in the utilization process of polysaccharides, which contribute greatly to the growth of probiotics. The prebiotic effect of polysaccharides could be affected by its chemical structure, its degree of branching, its solubility in water, and its degree of polymerization, among other factors [31].

PWBs have a positive effect on three probiotics, which indicates that PWBs encourage the proliferation of probiotics. Oligosaccharides are prebiotics that are widely used in yogurt. Prebiotics can be hydrolyzed by the enzymes in probiotics. Therefore, probiotics can hydrolyze and utilize carbohydrate prebiotics to produce energy and promote growth of probiotics.

\section{Materials and Methods}

\subsection{Materials and Chemicals}

White hyacinth beans (Batch number: 160101) were purchased from Xi'an Zaolutang Pharmaceutical Co., Ltd. (Xi'an, China). The samples were cleaned and dried before extraction. The bacteria used in this study were Lactobacillus bulgaricus LB6, Lactobacillus acidophilus LA5, and Bifidobacterium bifidum BB01, which were obtained from the School of Food and Biological Engineering, Shaanxi University of Science and Technology. Cellulase (10,000 U.g ${ }^{-1}$ ) was purchased from Zhaodong Beifang Enzyme Prepartion Co., Ltd. (Zhaodong, Heilongiiang, China). 2,2-Diphenyl-1-picrylhydrazy radicals (DPPH) were purchased from Yobios Co., Ltd. (Xi'an, China). All other chemicals were of analytical grade. 


\subsection{Enzyme-Assisted Extraction of PWBs}

Dried white hyacinth beans were pulverized and sifted through a 60 mesh sieve to obtain a homogeneous powder. The dried powder was dispersed in distilled water (water to material ratio, $\left.60.32-63.68 \mathrm{~mL} \cdot \mathrm{g}^{-1}\right)$. The $\mathrm{pH}$ of the suspension was adjusted to a designated value (7.46-8.14), and cellulase (2.53-2.87\%) was added. The reaction system was placed in a water bath at $60{ }^{\circ} \mathrm{C}$ for $3 \mathrm{~h}$. After the enzymolysis process, samples were rapidly heated at $90{ }^{\circ} \mathrm{C}$ for $10 \mathrm{~min}$. The extract solution was cooled, filtered, and concentrated. After centrifugation at $4000 \mathrm{rpm}$ for $10 \mathrm{~min}$, the crude extract was mixed with 3 volumes of ethanol and stored at $4{ }^{\circ} \mathrm{C}$ overnight. The protein in the crude polysaccharides was removed via the Sevag method [32]. Afterwards, the $95 \%\left(v \cdot v^{-1}\right)$ ethanol was added to precipitate the polysaccharide, filtered via filter paper under suction funnel, dissolved with distilled water, and centrifuged (4000 rpm for $10 \mathrm{~min}$ ). Finally, the supernatant was suitably diluted and the content of PWBs in the extract was evaluated via the phenol-sulfuric method using glucose as a standard [33]. The yield of PWBs was calculated by the following equations:

$$
\text { Polysaccharideyield }(\%)=\frac{\text { polysaccharideweight }(\mathrm{g})}{\text { whitehyacinthbeanweight }(\mathrm{g})} \times 100
$$

\subsection{Central Composite Design (CCD) and Statistical Analysis}

According to the results of single factor test and Plackett-Burman experiment, a central composite design was employed to optimize the extraction conditions. Each group conducted three parallel experiments. The coded values of variables were determined according to the following equation:

$$
x_{i}=\frac{X_{i}-X_{z}}{\Delta X_{i}}, \quad i=1,2,3 \ldots \ldots k
$$

where $x_{i}$ is the dimensionless coded value of an independent variable; $X_{i}$ is the true value of an independent variable; $X_{z}$ represents the true value of an independent variable at the center point; $\Delta X_{i}$ is step change of the real value of the variable i [34]. The coded values of different levels of each variable are shown in Table 3.

Table 3. The factors level coding table of the CCD.

\begin{tabular}{cccccc}
\hline Variable & \multicolumn{5}{c}{ Level } \\
\cline { 2 - 6 } & $\mathbf{- 1 . 6 8 2}$ & $\mathbf{- 1}$ & $\mathbf{0}$ & $\mathbf{1}$ & $\mathbf{1 . 6 8 2}$ \\
\hline A, pH value & 7.46 & 7.60 & 7.80 & 8.00 & 8.14 \\
B, cellulase $(\%)$ & 2.53 & 2.60 & 2.70 & 2.80 & 2.87 \\
C, Ratio $(v / w)$ of water $(m L)$ to material $(\mathrm{g})$ & 60.32 & 61.00 & 62.00 & 63.00 & 63.68 \\
\hline
\end{tabular}

A quadratic polynomial mathematical equation based on the data obtained from CCD was utilized to express the relationships between the variables. The developed equation in terms of the coded process variables are given below:

$$
\mathrm{R} 1=\beta_{0}+\beta_{1} \mathrm{~A}+\beta_{2} \mathrm{~B}+\beta_{3} \mathrm{C}+\beta_{12} \mathrm{AB}+\beta_{13} \mathrm{AC}+\beta_{23} \mathrm{BC}+\beta_{11} \mathrm{~A}^{2}+\beta_{22} \mathrm{~B}^{2}+\beta_{33} \mathrm{C}^{2}
$$

where $\mathrm{R} 1$ is the response value (polysaccharide yield), and $\mathrm{A}, \mathrm{B}$, and $\mathrm{C}$ represent the coded values of the $\mathrm{pH}$ value, the cellulase, and the ratio of water to material, respectively. $\beta_{0}$ is the constant regression coefficient. $\left(\beta_{1}, \beta_{2}, \beta_{3}\right),\left(\beta_{11}, \beta_{22}, \beta_{33}\right)$, and $\left(\beta_{12}, \beta_{23}, \beta_{13}\right)$ are the regression coefficient for the linear, quadratic, and interaction terms, respectively.

Design Expert 8.0.6 software (Stat-Ease. Inc., Minneapolis, MN, USA) was utilized to investigate the experimental data statistically. Multiple regression analysis was applied to experimental data to construct a quadratic polynomial mathematical model for the response. 


\subsection{Antioxidant Activity of Polysaccharides}

\subsubsection{An Assay of Scavenging Hydroxyl Radical Activity}

The scavenging ability of PWBs on hydroxyl radicals was measured according to the Fenton method [35] with some modifications. The reaction mixture contained $2 \mathrm{~mL}$ of a phosphate buffer $\left(0.2 \mathrm{~mol} \cdot \mathrm{L}^{-1}, \mathrm{pH} 7.4\right), 2 \mathrm{~mL}$ of an orthophenanthroline solution $\left(0.1 \mathrm{mmol} \cdot \mathrm{L}^{-1}\right), 1 \mathrm{~mL}$ of a ferrous sulfate $\left(\mathrm{FeSO}_{4}\right)$ solution $\left(0.15 \mathrm{mmol} \cdot \mathrm{L}^{-1}\right), 1 \mathrm{~mL}$ of a hydrogen peroxide $\left(\mathrm{H}_{2} \mathrm{O}_{2}\right)$ solution $(0.01 \%)$, and $1 \mathrm{~mL}$ of samples. After incubation at $37^{\circ} \mathrm{C}$ for $60 \mathrm{~min}$, the absorbance of different mixtures was measured at $510 \mathrm{~nm}$ with a spectrophotometer. Ascorbic acid $\left(\mathrm{V}_{\mathrm{C}}\right)$ was used as a reference material, and all tests were carried out in triplicate. The scavenging activity of polysaccharides on hydroxyl radicals was calculated using the following equation:

$$
\text { Scavengingactivity }(\%)=\left[\left(\mathrm{A}_{2}-\mathrm{A}_{0}\right) /\left(\mathrm{A}_{1}-\mathrm{A}_{0}\right)\right] \times 100
$$

where $A_{0}$ is the absorbance of the reaction solution without PWBs, $A_{2}$ is the absorbance of the sample with the $\mathrm{H}_{2} \mathrm{O}_{2}$ solution, and $\mathrm{A}_{1}$ is the absorbance of the sample under conditions similar to that of $\mathrm{A}_{2}$, but with water instead of an $\mathrm{H}_{2} \mathrm{O}_{2}$ solution.

\subsubsection{Assay of Superoxide Radical Scavenging Activity}

The activity of scavenging superoxide radicals was tested via the auto-oxidation of pyrogallic acid as in [36] but with a slight modification. In this experiment, the reaction mixture contained $2.5 \mathrm{~mL}$ of a Tris- $\mathrm{HCl}$ buffer $\left(0.05 \mathrm{~mol} \cdot \mathrm{L}^{-1}, \mathrm{pH} 8.2\right), 0.1 \mathrm{~mL}$ of a pyrogallic acid solution $\left(0.01 \mathrm{~mol} \cdot \mathrm{L}^{-1}\right)$, and $0.4 \mathrm{~mL}$ of a polysaccharide solution. The polysaccharides and Tris- $\mathrm{HCl}$ were incubated at $25{ }^{\circ} \mathrm{C}$ for $20 \mathrm{~min}$, and pyrogallic acid was then added to the mixture. After shaking, the absorbance of the sample at $325 \mathrm{~nm}$ was measured using a spectrophotometer. The scavenging activity of polysaccharides on superoxide radicals was calculated by the following equation:

$$
\text { Scavenging activity }(\%)=\left[\left(\mathrm{A}_{0}-\mathrm{A}_{1}\right) / \mathrm{A}_{0}\right] \times 100
$$

where $A_{0}$ is the absorbance of the control (without PWBs), and $A_{1}$ is the absorbance of the mixture containing PWBs.

\subsubsection{Assay of DPPH Radical Scavenging Activity}

The scavenging activity of polysaccharides on 2,2-diphenyl-1-picrylhydrazyl (DPPH) radicals was measured according to the method by Kazuko et al. [37] but with a slight modification. Two milliliters of an aliquot of a DPPH solution $\left(0.2 \mathrm{mmol} \cdot \mathrm{L}^{-1}\right)$ in anhydrous ethanol and $2 \mathrm{~mL}$ of sample in different concentrations $\left(1.0,2.0,4.0,6.0,8.0\right.$ and $\left.10.0 \mathrm{mg} \cdot \mathrm{mL}^{-1}\right)$ were mixed together, and left to sit for $40 \mathrm{~min}$ after shaking. Ethanol with a concentration of $50 \%$ was used as the blank group. The scavenging ability was measured by determining the absorbance of the mixture at $517 \mathrm{~nm}$, and all tests were carried out in triplicate. When proton radicals from DPPH are scavenged by polysaccharides, its purple color rapidly fades [38], which changes the absorption value at $517 \mathrm{~nm}$. The scavenging activity of polysaccharides on DPPH radicals was calculated according to the following formula:

$$
\text { Scavengingactivity }(\%)=\left[1-\left(\mathrm{A}_{\mathrm{i}}-\mathrm{A}_{\mathrm{j}}\right) / \mathrm{A}_{0}\right] \times 100
$$

where $A_{0}$ is the absorbance of the DPPH solution without the samples, $A_{i}$ is the absorbance of the polysaccharides with the DPPH solution, and $A_{j}$ is the absorbance of the sample under conditions similar to $A_{i}$, but with water instead of the DPPH solution. 


\subsection{Effect of PWBs on the Growth of Three Selected Probiotics}

An MRS medium (lactose: $20 \mathrm{~g}$, peptone: $10 \mathrm{~g}$, sodium acetate: $3 \mathrm{~g}, \mathrm{MgSO}_{4}: 0.2 \mathrm{~g}, \mathrm{MnSO}_{4}: 0.05 \mathrm{~g}$, L-cysteine hydrochloride: $0.5 \mathrm{~g}$, Tween $80: 1 \mathrm{~mL}$, dissolved in $1000 \mathrm{~mL}$ of distilled water (pH of 6.2)) and PWBs were sterilized at $121^{\circ} \mathrm{C}$ for $15 \mathrm{~min}$. After cooling to room temperature, L. acidophilus LA5, B. bifidum BB01, and L. bulgaricus LB6 were incubated in the MRS medium ( $3 \%$ inoculum size) at $37^{\circ} \mathrm{C}$. Five different concentrations of PWBs $(0.05 \%, 0.10 \%, 0.15 \%, 0.20 \%$, and $0.25 \%$ in volume) were added to the medium. There were no polysaccharides in the blank group. The growth of three probiotics was assessed by determining the $\mathrm{OD}_{600}$ and the $\mathrm{pH}$ value of the culture solution every $4 \mathrm{~h}$ from the 14th hour (recorded 3 times in total).

\section{Conclusions}

In this study, cellulase-assisted extraction was optimized to extract PWBs. A CCD was employed to optimize the extraction process. The optimum parameters of PWB extraction obtained from the statistical analysis were as follows: a $\mathrm{pH}$ of 7.79 , a cellulase of $2.73 \%$, and a ratio of water to material of 61.39. Under these optimum conditions, the predicted polysaccharide yield reached a maximum of $3.37 \%$. The confirmatory experiments were conducted to test and verify the optimized result. Under the determined conditions, the mean value of the polysaccharide yield was $(3.32 \pm 0.03) \%$. In addition, the PWBs showed different scavenging activity with respect to hydroxyl radicals, superoxide radicals, and DPPH radicals. The scavenging ability of PWBs with respect to these three radicals was lower than that of $V_{C}$. Therefore, PWBs are potential natural antioxidants in functional food and medicinal products. Furthermore, our results indicate that PWBs might promote the growth of L. acidophilus LA5, B. bifidum BB01, and L. bulgaricus LB6 and can be employed as novel prebiotics.

Acknowledgments: The work was partly supported by the Doctoral Scientific Research Fund from Shaanxi University of Science and Technology (No. 2017BJ-04), the Science and Technology Project of Xi'an City (No.XJR1506-(10)), and the Science and Technology Project of Baqiao District (No. 2016-(7)).

Author Contributions: Guo-Wei Shu conceived and designed the experiments; Yun-Xia He performed the experiments; Guo-Wei Shu and Ji-Li Cao analyzed the data; He Chen contributed reagents/materials/analysis tools; Yun-Xia He, Ni Lei and Li Chen wrote and revised the paper.

Conflicts of Interest: The authors declare no conflict of interest.

\section{References}

1. Choudhury, F.K.; Rivero, R.M.; Blumwald, E.; Mittler, R. Reactive oxygen species, abiotic stress and stress combination. Plant J. 2017, 90, 856-867. [CrossRef] [PubMed]

2. Cadenas, E.; Davies, K.J. Mitochondrial free radical generation, oxidative stress, and aging. Free Radic. Biol. Med. 2000, 29, 222-230. [CrossRef]

3. Ksouri, R.; Ksouri, W.M.; Jallali, I.; Debez, A.; Magné, C.; Hiroko, I. Medicinal halophytes: Potent source of health promoting biomolecules with medical, nutraceutical and food applications. Crit. Rev. Biotechnol. 2012, 32, 289-326. [CrossRef] [PubMed]

4. Frankel, E.N. Antioxidants in lipid foods and their impact on food quality. Food Chem. 1996, 57, 51-55. [CrossRef]

5. Moein, M.; Moein, S.; Fard, T.B.; Sabahi, Z. Scavenging evaluation of different free radicals by three species of ziziphus, and their fractions. Iran. J. Sci. Technol. A 2017, 41, 249-255. [CrossRef]

6. Botterweck, A.A.; Verhagen, H.; Goldbohm, R.A.; Kleinjans, J.; Brandt, P.A. Intake of butylated hydroxyanisole and butylated hydroxytoluene and stomach cancer risk: Results from analyses in the netherlands cohort study. Food Chem. Toxicol. 2000, 38, 599-605. [CrossRef]

7. Petera, B.; Delattre, C.; Pierre, G.; Wadouachi, A.; Elboutachfaiti, R.; Engel, E. Characterization of arabinogalactanrich mucilage from cereus triangularis cladodes. Carbohydr. Polym. 2015, 127, 372-380. [CrossRef] [PubMed]

8. Wang, Z.; Wang, C.; Yue, Q. Extraction of polysaccharides from Phellinus nigricans, mycelia and their antioxidant activities in vitro. Carbohydr. Polym. 2014, 99, 110-115. [CrossRef] [PubMed] 
9. Delattre, C.; Pierre, G.; Gardarin, C.; Traikia, M.; Elboutachfaiti, R.; Isogai, A. Antioxidant activities of a polyglucuronic acid sodium salt obtained from tempo-mediated oxidation of xanthan. Carbohydr. Polym. 2015, 116, 34-41. [CrossRef] [PubMed]

10. Xu, W.; Zhang, F.; Luo, Y.; Ma, L.; Kou, X.; Huang, K. Antioxidant activity of a water-soluble polysaccharide purified from Pteridium Aquilinum. Carbohydr. Res. 2008, 344, 217-222. [CrossRef] [PubMed]

11. Kardosová, A.; Machová, E. Antioxidant activity of medicinal plant polysaccharides. Fitoterapia 2006, 77, $367-373$. [CrossRef] [PubMed]

12. Wang, Q.; Sun, Y.; Yang, B.; Wang, Z.; Liu, Y.; Cao, Q. Optimization of polysaccharides extraction from seeds of Pharbitis nil and its anti-oxidant activity. Carbohydr. Polym. 2014, 102, 460-466. [CrossRef] [PubMed]

13. Ge, Q.; Huang, J.; Mao, J.W.; Gong, J.Y.; Zhou, Y.F.; Huang, J.X. Optimization of total polysaccharide extraction from Herba Lophatheri using RSM and antioxidant activities. Int. J. Biol. Macromol. 2014, 67, 37-42. [CrossRef] [PubMed]

14. Subagio, A. Characterization of hyacinth bean (Lablab purpureus (L.) sweet) seeds from Indonesia and their protein isolate. Food Chem. 2006, 95, 65-70. [CrossRef]

15. You, Q.; Yin, X.; Zhao, Y. Enzyme assisted extraction of polysaccharides from the fruit of Cornus officinalis. Carbohydr. Polym. 2013, 98, 607-610. [CrossRef] [PubMed]

16. Singdevsachan, S.K.; Auroshree, P.; Mishra, J.; Baliyarsingh, B.; Tayung, K.; Thatoi, H. Mushroom polysaccharides as potential prebiotics with their antitumor and immunomodulating properties: A review. Bioact. Carbohydr. Diet. Fibre 2016, 7, 1-14. [CrossRef]

17. Lei, N.; Chen, H.; Feng, J.H. Optimization of extraction of polysaccharides from white hyacinth bean using Plackett-Burman and steepest ascent experiment. Carpath. J. Food Sci. Technol. 2016, 8, 73-82.

18. Li, X.; Han, L.; Li, Y.; Zhang, J.; Chen, J.; Lu, W. Protective effect of sinapine against hydroxyl radical-induced damage to mesenchymal stem cells and possible mechanisms. Chem. Pharm. Bull. 2016, 64, 319-325. [CrossRef] [PubMed]

19. Liu, F.; Gong, J.; Yang, Y.; Dong, J. Study on Antioxidant Activity In Vitro of Four Kinds of Herbal Polysaccharides. Henan Sci. 2009, 27, 1212-1215. [CrossRef]

20. Mohammad, A.M.; Koji, Y.; Toshiki, M.; Yumi, N.; Katsumi, S.; Hiroaki, S. Superoxide anion radical scavenging activities of herbs and pastures in northern Japan determined using electron spin resonance spectrometry. Int. J. Biol. Sci. 2007, 3, 349-355.

21. Chen, Y.; Xie, M.Y.; Nie, S.P.; Li, C.; Wang, Y.X. Purification, composition analysis and antioxidant activity of a polysaccharide from the fruiting bodies of Ganoderma atrum. Food Chem. 2008, 107, 231-241. [CrossRef]

22. Krings, U.; Berger, R.G. Antioxidant activity of some roasted foods. Food Chem. 2001, 72, 223-229. [CrossRef]

23. Li, P.; Zhou, L.; Yan, M.; Mao, Z. Extraction optimization of polysaccharide from Zanthoxylum bungeanum using RSM and its antioxidant activity. Int. J. Biol. Macromol. 2015, 72, 19-27. [CrossRef] [PubMed]

24. Zhao, L.; Dong, Y.; Chen, G.; Hu, Q. Extraction, purification, characterization and antitumor activity of polysaccharides from Ganoderma lucidum. Carbohydr. Polym. 2010, 80, 783-789. [CrossRef]

25. Chen, H.; Zhang, M.; Qu, Z.; Xie, B. Antioxidant activities of different fractions of polysaccharide conjugates from green tea (Camellia Sinensis). Food Chem. 2008, 106, 559-563. [CrossRef]

26. Ramnani, P.; Chitarrari, R.; Tuohy, K. In vitro fermentation and prebiotic potential of novel low molecular weight polysaccharides derived from agar and alginate seaweeds. Anaerobe 2012, 18, 1-6. [CrossRef] [PubMed]

27. Mueller, M.; Čavarkapa, A.; Unger, F.M.; Viernstein, H.; Praznik, W. Prebiotic potential of neutral oligoand polysaccharides from seed mucilage of Hyptis suaveolens. Food Chem. 2017, 221, 508-514. [CrossRef] [PubMed]

28. Madhukumar, M.; Muralikrishna, G. Structural characterisation and determination of prebiotic activity of purified xylo-oligosaccharides obtained from Bengal gram husk (Cicer arietinum L.) and wheat bran (Triticum aestivum). Food Chem. 2010, 118, 215-223. [CrossRef]

29. Hwang, P.A.; Phan, N.N.; Lu, W.J.; Hieu, B.T.N.; Lin, Y.C. Low-molecular-weight fucoidan and high-stability fucoxanthin from brown seaweed exert prebiotics and anti-inflammatory activities in Caco-2 cells. Food Nutr. Res. 2016, 60, 32033. [CrossRef] [PubMed]

30. He, Z.; Wang, X.; Li, G.; Zhao, Y.; Zhang, J.; Niu, C. Antioxidant activity of prebiotic ginseng polysaccharides combined with potential probiotic Lactobacillus plantarum C88. Int. J. Food Sci. Technol. 2015, 50, 1673-1682. [CrossRef] 
31. Biedrzycka, E.; Bielecka, M. Prebiotic effectiveness of fructans of different degrees of polymerization. Trends Food Sci. Technol. 2004, 15, 170-175. [CrossRef]

32. Sevag, M.G.; Lackman, D.B.; Smolens, J. The isolation of the components of streptoeoeeal nueleoproteins in serologieally active form. J. Biol. Chem. 1938, 124, 42-49.

33. Dubois, M.; Gilles, K.A.; Hamilton, J.K.; Rebers, P.A.; Smith, F. Colorimetric method for determination of sugars and related substances. Anal. Chem. 1956, 28, 350-356. [CrossRef]

34. Minjares-Fuentes, R.; Femenia, A.; Garau, M.C.; Candelas-Cadillo, M.G.; Simal, S.; Rosselló, C. Ultrasoundassisted extraction of hemicelluloses from grape pomace using response surface methodology. Carbohydr. Polym. 2016, 138, 180-191. [CrossRef] [PubMed]

35. Smirnoff, N.; Cumbes, Q.J. Hydroxyl radical scavenging activity of compatible solutes. Phytochemistry 1989, 28, 1057-1060. [CrossRef]

36. Marklund, S.; Marklund, G. Involvement of the superoxide anion radical in the autoxidation of pyrogallol and a convenient assay for superoxide dismutase. Eur. J. Biochem. 1974, 47, 469-474. [CrossRef] [PubMed]

37. Kazuko, S.; Kuniko, F.; Keiko, Y.; Takashi, N. Antioxidative properties of xanthan on the autoxidation of soybean oil in cyclodextrin emulsion. J. Agric. Food Chem. 1992, 40, 945-948.

38. Yamaguchi, T.; Takamura, H.; Matoba, T.; Terao, J. HPLC method for evaluation of the free radical-scavenging activity of foods by using 1,1-diphenyl-2-picrylhydrazyl. Biosci. Biotechnol. Biochem. 2014, 62, 1201-1204. [CrossRef] [PubMed]

Sample Availability: Samples of the compounds are available from the authors.

(C) 2017 by the authors. Licensee MDPI, Basel, Switzerland. This article is an open access article distributed under the terms and conditions of the Creative Commons Attribution (CC BY) license (http://creativecommons.org/licenses/by/4.0/). 